\title{
Una ética hacia el otro-sufriente. La sensibilidad en tanto fuente de la responsabilidad en Richard Rorty y Emmanuel Lévinas ${ }^{1}$
}

\author{
Ethics towards the suffering one. The sensitivity as \\ responsibility source in Richard Rorty and \\ Emmanuel Levinas
}

\section{Uma ética para o outro- sofrente. A sensibilidade como fonte de responsabilidade em Richard Rorty e Emmanuel Lévinas}

Mag. Mario Eduardo Farías G. ${ }^{2}$

Recibido: 09/08/2014 · Aceptado: 10/09/2014

\begin{abstract}
Resumen
Este artículo presenta una tesis fundamental en R. Rorty, que se ocupa de repensar la ética desde un nuevo derrotero, la sensibilidad. Se trata de un extracto que pretende presentar una cierta línea de reflexión que aborda la problemática de la ética hodierna y su urgencia atingente a situaciones de injusticia y humillaciones en no pocas sociedades que han postergado de derechos fundamentales a una gran mayoría de seres humanos. Por su parte, la filosofía quiere ser un "acuso recibo" con una línea de intelectuales que ven con preocupación el curso de una historia que se conduce a espaldas de las necesidades de los hombres. Efectivamente, la ética será el foco centrípeto hacia el cual convergerán distintas reflexiones con el afán de responder a la debacle moral en Occidente.
\end{abstract}

Palabras clave: ética - sufriente - sensibilidad - responsabilidad - Rorty.

1 Este texto corresponde a mi tesis de Magíster en Filosofía.

2 Mag. in Teologia, Pontifitia Università Gregoriana di Roma. Mag., en Filosofía por la Universidad Alberto Hurtado, Chile. Profesor adjunto de la Facultad de Ciencias Religiosas y Filosofía, Universidad Católica Silva Henríquez. mfariasg@ucsh.cl 


\begin{abstract}
This paper presents a fundamental thesis by R. Rorty, aimed to rethink ethics from sensitivity as a new perspective. This is an abstract intended to present a certain line of reflection that addresses the issue of daily ethics and its emergency in relation to situations of injustice and humiliation in many societies that have postponed fundamental rights of a vast majority of human beings. Meanwhile, philosophy wants to be an "acknowledgement of receipt" with a line of intellectuals who are concerned about the course of a story that leads behind the needs of men. Indeed, ethics is the centripetal focus toward which different reflections converge in an effort to respond to the moral debacle in the West.
\end{abstract}

Key words: ethics - suffering -sensibility - responsibility - Rorty

\title{
Resumo
}

Este artigo apresenta uma tese fundamental em R. Rorty, que trabalha no campo de repensar a ética desde uma nova rota, a sensibilidade. Tratase de um extrato que pretende apresentar certa linha de reflexão que aborda o problema da ética hodierna e sua urgência referente a situações de injustiça e humilhações em não poucas sociedades que adiaram os direitos fundamentais a uma grande maioria dos seres humanos. Por sua parte, a filosofia pretende ser um "Acuso recibo" com uma linha de intelectuais que vê com preocupação o curso de uma história que se conduz as costas das necessidades dos homens. Efetivamente, a ética será o foco centrípeto na direção que convergem distintas reflexões num esforço para responder à crise moral no Ocidente.

Palavras-chave: ética - sofrente - sensibilidade - responsabilidade - Rorty

\section{Síntoma y reorientación de la filosofía reciente}

La relevancia de la filosofía ética y política se muestra hoy con especial intensidad, pues trata de resolver los problemas de la vida práctica en las sociedades modernas, y en este sentido la filosofía en su vertiente ético-política puede ayudar a iluminar aquella tarea práctica. Pero ¿por qué la filosofía se atribuye esta competencia, si ella se ocupa de cuestiones teóricas? ¿Acaso no existen disciplinas que inciden directamente en los procesos de cambios sociales? No se trata de un programa práctico en materias sociopolíticas sino más bien de pensar el mundo en su devenir y elaborar un instrumental teórico adecuado que ilumine la tarea de su reconstrucción. La génesis de todo pensamiento filosófico -de última data- tiene como trazo principal las 
preocupaciones vitales de la existencia individual y comunitaria de los seres humanos. Por una parte, el mundo de la vida aparece como tópico central en las reflexiones filosóficas en cuanto contribuyen a una mejor elucidación del presente, como así también nos ayudan a dibujar futuros más deseables y justos para el ser humano ${ }^{3}$. En efecto, la filosofía no dirige el mundo, pero sí puede contribuir de manera indirecta a que el mundo sea un lugar mejor de lo que es. Ella no puede jamás crear de una manera inmediata, como afirma Heidegger, las formas de acción que susciten una acción en la historia ${ }^{4}$, pero sí desea influir sobre el curso de las cosas pensando un orden más justo en el contexto de las sociedades pluralistas.

En nuestra historia reciente se revaloriza la reflexión ético-práctica como salida a la crisis o agotamiento de la racionalidad moderna. En esta línea, el estudio de R. Bernstein ${ }^{5}$ es significativo al mostrar el fin de los valores y el paso al compromiso ético más acentuado en nuestra contemporaneidad.

Ahora bien, la pregunta que surge es: ¿por qué estalla este giro ético en la filosofía? El discurso de la tradición filosófica como explicación última de la realidad se ha vuelto estéril en las relaciones intersubjetivas. La filosofía en su pretensión totalizante ha negado el individuo, la diferencia, la pluralidad. Se trata de superar el paradigma filosófico centrado en la ontología y abocarse al sujeto humano. El diagnóstico que sitúa el giro ético en la filosofía, da cuenta de la poca efectividad de ésta en las relaciones sociales, en el trato justo entre los componentes de la sociedad. Efectivamente el afán de objetividad de la filosofía no garantiza un progreso moral, una mayor comprensión del sujeto humano. En este sentido la filosofía, si bien no resuelve directamente las cuestiones sociales y políticas, sí puede ayudar a iluminar la reflexión ética dirigiendo las decisiones prácticas en torno a la existencia humana.

3 P. Salvat, El porvenir de la equidad, 13.

4 F. de Towarnicki et al. Conversación con Heidegger, 20-26.

5 Cf. R. Bernstein. "Serious Play: The ethical-political horizon of Jacques Derrida", 93-115. 
Hablar de la filosofía contemporánea será una forma de referirse a la filosofía actual, que entre sus características destaca la reflexión éticopolítica, asunto que atraviesa toda la investigación. Esta posición no nos lleva a sortear el amplio y complejo panorama de la razón contemporánea, aunque sí presentaremos igualmente un esbozo general de la racionalidad actual, el que nos permitirá entender el giro ético de la filosofía. He escogido el adjetivo "contemporáneo(a)" para referirme a la filosofía reciente, que no necesariamente se agota en la filosofía postmoderna, sino que también se refiere a la modernidad, pues de alguna manera ambas conviven como filosofía contemporánea ${ }^{6}$. Inclusive no es fácil dilucidar lo que sea la filosofía postmoderna, pues carece de una identidad unívoca provocando en gran parte una confusión de "significados". El rótulo "postmoderno", "postmodernos" o "postmodernidad" es muy flexible a la hora de saber si se refiere a una actitud política o una novela ${ }^{7}$. Se trata de un concepto bastante equívoco de esta última época cuya característica principal es la de una racionalidad todavía confusa, heterogénea, atravesada de una parte por una actitud de des-regulación de las propuestas normativas vigentes, y por otra, por un interés por la vida práctica, o sea por valorar las implicaciones éticas que comporta este ejercicio de deconstrucción ${ }^{8}$. Efectivamente, la filosofía se toma la palestra de los problemas morales y políticos porque "no rehúye la responsabilidad frente al mundo, sino que, más bien, anhela y busca su pertinencia social e histórica" ${ }^{\prime}$.

\subsection{Crisis de la filosofía reciente}

El panorama de la filosofía reciente trae una mixtura de inquietudes que, si bien se caracterizan por este giro hacia una filosofía práctica, que se sitúa desde diferentes ámbitos dentro del pensamiento postmo-

6 La cuestión de la postmodernidad como "otro" período o "consumación" de la modernidad aún se encuentra abierta. Para efectos de la presente investigación, no entraremos en el debate, sino más bien presentamos algunas líneas de la filosofía reciente que nos ayudan a encuadrar el escenario en el cual se inserta nuestra investigación.

7 Cf. R. Rorty. Cuidar la libertad, 179.

8 Cf. Z. Bauman. La posmodernidad y sus descontentos, 23ss.

9 M. Figueroa et al. Filosofía y Solidaridad, 11. 
derno como la filosofía ética, pragmática, lingüística, política, también ello implica la valoración ineludible del individuo, la subjetividad y la diferencia. No se trata de rehabilitar una ética de vieja data, sino más bien de proponer una ética sobre los nuevos cánones de la filosofía contemporánea. Por eso, es conveniente presentar con una mirada más acuciosa aquellos síntomas característicos de la filosofía reciente con el fin de dilucidar lo mejor posible el giro ético. En efecto, se proyecta la construcción de una nueva racionalidad que se presenta como falible, plural y permeable al trabajo de la experiencia tal como afirma Samuel Cabanchik, el que nos da algunas pistas para delinear los trazos más sintomáticos de la postmodernidad ${ }^{10}$ : a) La crisis del fundamento, que dice relación a la crisis de posiciones fundacionistas en materia de conocimiento y en el terreno de la metafísica. b) La crisis de la idea de representación, noción que se concibe como un medio de unión y a la vez separación de la mente -o lenguaje- por un lado, y los hechos, las cosas o el mundo por el otro. c) Sociologización del pensamiento y del lenguaje, punto de vista que afirma que toda realidad es un producto colectivo social, o sea la autoridad epistémica de la primera persona singular, se traslada a la primera persona plural. d) A partir de aquí, existe una marcada tendencia a las tesis deflacionarias en relación al significado y a la verdad. e) Finalmente, se instala una nueva racionalidad, que quizá es el rasgo más característico e integrador de los distintos trazos antes mencionados. Se trata de una razón que se presenta como falible, plural y permeable al trabajo de la experiencia.

En tal panorama entran en crisis las doctrinas omnicomprensivas y se sitúa la constitución de espacios-tiempos plurales, como efecto de la desregulación ética y política. Pero ¿con qué finalidad? Como afirma Bauman, con "la esperanza de hacer las cosas mejores de lo que son, dado que, por el momento, no son suficientemente buenas"11. En este sentido, si la modernidad se caracterizaba esencialmente por su ambición en las meta-narrativas ${ }^{12}$, debemos admitir que la razón

10 Cf. S. Cabanchik et al. El giro pragmático en la filosofía, 14-17.

11 Z. Bauman. La posmodernidad y sus descontentos, 102.

12 Tal como afirma J. L. Rodríguez (Crítica de la razón postmoderna, 71): cuando 
postmoderna carece de anclajes en relación a la Modernidad, pues tal como se teoriza en El Príncipe de Maquiavelo, el sujeto se convierte en actor y protagonista del acontecer social y político, con poder de doblegar a la fortuna, a la fuerza del destino que no pocas veces le ha dado las espaldas al hombre. Consecuentemente se comprenderá al hombre como máquina productiva de normas, horizontes y códigos. Por último se yergue con pleno poder lo subjetivo, lo que desmorona la universalidad y la identidad como coordenadas típicas de los metarrelatos. La subjetividad postmoderna pregona la disidencia en pro de la individualidad.

La postmodernidad se cierne sobre una poderosa insatisfacción, si bien sobre las metanarrativas, pero en cierto sentido con la intención de redefinir los problemas capitales de la filosofía, evitando la inmovilidad por apuntar o proyectar estrategias éticas y políticas ${ }^{13}$. Es decir, se trata de evitar la quietud de una filosofía que sea incapaz de proyectar criterios que han de regir la praxis ética y política. Asistimos a una claudicación del pensamiento clásico y a la entronización de la subjetividad, la diferencia y la otredad. Efectivamente, esta desconfianza o actitud crítica bajo la forma de desregulación se afianza en la diferencia, que en la vivencia se proyecta como pluralidad, que al final arremete contra la universalidad en pos de la recreación subjetiva o grupal ${ }^{14}$. Este último punto es crucial en la definición de la hipótesis que queremos validar. Pues desde la subjetividad los filósofos que nos acompañarán articulan sus teorías éticas centradas en la responsabilidad hacia el otro. Tal como afirma Cohen:

"La ética en su oposición metódica a todo lo sensible y empírico en el ser humano, saca la vigorosa consecuencia de que debe en primerísimo lugar despojar al Yo del ser humano de

define el metarrelato como una configuración discursiva que pretende establecer la geografía de una totalización que, en tanto tal, facilita la inteligibilidad del conjunto de los aspectos de la vida individual y social. El rasgo fundamental de los metarrelatos es la finalidad, que permitiría imaginar el futuro, para constituir un telos histórico que es el que arroja luz sobre la totalidad de las dimensiones de la temporalidad.

13 Cf. J. L. Rodríguez. Crítica de la razón postmoderna, 83-84.

14 Cf. J. L. Rodríguez. Crítica de la razón postmoderna, 163. 
toda individualidad, para devolvérsela, desde una cima más elevada... En la ética, el Yo del ser humano se convierte en el Yo de la humanidad"155.

\subsection{Planteamiento del problema: la sensibilidad}

A partir del marco del giro ético en el pensamiento de Rorty, nos abocamos a encontrar en el autor aquellos elementos que nos permitan afirmar que en él "la responsabilidad hacia el otro", se sustenta en la sensibilidad hacia el otro. Efectivamente, ambos autores se ocupan del desafío de plantear una ética hacia-el-otro: el extranjero, la viuda, el musulmán, la persona de color. Rorty en el tratamiento del concepto de solidaridad, hace una distinción entre el "ellos" y el "nosotros". En efecto, el "ellos" aún no es causa de responsabilidad ética, de proximidad. Sin embargo, cuando se trata de "uno-de-nosotros" provoca el movimiento de la responsabilidad u obligación moral hacia los "otros" en cuanto uno de nosotros.

En este autor, lo que lo ha llevado a preguntarse ¿por qué me incumbe(n) el (los) otro(s)? ¿Por qué la responsabilidad hacia el "otro"?, se debe fundamentalmente al fracaso de las teorías abstractas, a-históricas y universalistas que al final no han sido mejores que las motivaciones del ironista liberal (Rorty) o como por ejemplo la metafísica de la alteridad de Lévinas, para promover una eticidad por el otro. Rorty se la emprende contra el paradigma filosófico centrado en la objetividad que ha instalado la "idea" unívoca de que todos somos iguales, apoyada en constructos uniformantes y totalizantes (Lévinas) que no admiten al "extraño", al "extranjero", al lejano "ellos" de Rorty. Ambos de alguna manera realizan una deconstrucción de la filosofía occidental con un propósito ético, pero sostenido en los arcanos de la persona humana: su susceptibilidad o sensibilidad por el otro-sufriente.

15 H. Cohen. Religión de la razón desde las fuentes del judaísmo, 3. 
Algunos evocando a Badiou o Ricoeur afirman que pensadores como Rorty fundamentan la responsabilidad ética en el sufrimiento: "el sufrimiento obliga"16. Pero no pocas veces el sufrimiento de muchos en los campos de exterminio o en las limpiezas étnicas -por citar lamentablemente algunos de estos hitos-no rompieron las barreras de contención de las conciencias éticas impostadas así desde la objetividad. ¿Acaso las víctimas no merecían tal consideración ética a partir del sufrimiento? ¿Es que no eran humanos como para sentir conmiseración por ellos? ¿No se trata de escudriñar más bien en "la sensibilidad humana"? Efectivamente, el sufrimiento por sí solo no basta. Se trata de visitar los recónditos lugares relegados en gran parte por el pensamiento occidental: la sensibilidad por el que sufre, para que el que padece miserias sea alcanzado, en la inmediatez de la comunidad del "nosotros" o el espacio del "yo-otro", por la responsabilidad.

Rorty como ironista liberal en su teoría ética basada en la solidaridad se desprende de cualquier argumento de carácter universal y racional. La solidaridad se construye a partir de la susceptibilidad hacia la humillación. Pero ésta surge en la convivencia social, pues el ironista liberal distingue la vida privada como espacio de autorrealización, y la vida pública o social como espacio de la solidaridad. Por ende, la solidaridad humana no es cosa que dependa de la participación de una verdad metafísica sino más bien es "cuestión de compartir una esperanza egoísta común: la esperanza de que el mundo de uno -las pequeñas cosas en torno a las cuales uno ha tejido el propio léxico último- no será destruido"17. Efectivamente para Rorty la "solidaridad" es la capacidad de responder a la humillación humana. "La responsabilidad hacia los demás" es una forma de nombrar la solidaridad rortyana, y aquí el término "responsabilidad" lo utilizo en un sentido lato, o sea de su definición latina responsum como capacidad de responder de algo o alguien.

La hipótesis que se formula a partir de la teoría ética de Rorty afirma que en la "la responsabilidad hacia el otro" (sufriente), la sensibilidad

16 P. Hallward. Badiou: a subjetct to truth, 256.

17 R. Rorty. Contingencia, ironía y solidaridad, 110. 
opera como fuente de obligación ética. A la pregunta ¿cómo se realiza la responsabilidad hacia el otro?, desde el pragmatismo liberal de Rorty podemos responder que: la "susceptibilidad" o "sensibilidad" de Rorty la entiende como la disposición sensible hacia el sufrimiento de los demás en tanto fuente de la ética, la que compromete una relación de responsabilidad con los demás ${ }^{18}$.

\section{Rorty y la sensibilidad como fuente de la solidaridad}

Si bien Rorty no se autodefine como un filósofo de los fundamentos, ello no elimina que en su trabajo intelectual, intente presentar las fuentes de la vida ética. En este sentido, más que buscar fundamentos que justifiquen la vida ética, trabaja por orientar el comportamiento moral desde una ética basada en la "sensibilidad". ¿Por qué la sensibilidad? Rorty como ironista liberal plantea en su proyecto, una sociedad individualista y pluralista en la cual sus miembros puedan autocrearse de modo que las cosas puedan marchar mejor en tanto individuos ${ }^{19}$. Pero en una sociedad con graves crisis sociales ¿por qué recalcar aún más la vida privada? ¿Acaso esta postura centrada en la vida privada no atenta contra los intereses comunes de la sociedad? Rorty, a partir de una distinción entre la vida privada y la vida pública ${ }^{20}$, afirma que los individuos buscan "su mejor yo posible" pero ello no implica perder las esperanzas de una sociedad más justa, menos cruel. Por ende, en esta búsqueda de autocreación, de una redescripción propia, debemos cuidarnos de no humillar a los demás. Pues para Rorty el único vínculo social que se necesita es el de ser sensibles a la humillación ${ }^{21}$. En efecto, sin fundamentos basados en imperativos categóricos compartidos por lo privado y lo público, Rorty vislumbra que la "disposición de ser susceptibles de padecer dolor" es algo común en todos los seres humanos. A propósito afirma que en los:

18 S. Critchley. "Deconstrucción y pragmatismo. ¿Es Derrida un ironista privado o un liberal público?", 74-75.

19 Cf. R. Rorty. Contingencia, ironía y solidaridad, 104.

20 R. Rorty. Contingencia, ironía y solidaridad, 101.

21 R. Rorty. Contingencia, ironía y solidaridad, 106. 
"propósitos públicos no importa si el léxico de cada uno es diferente del de los demás, en la medida en que haya coincidencia suficiente para que cada uno disponga de algunas palabras con las cuales expresar que es deseable tomar parte en las fantasías de las otras personas tanto como en la propias" 22 .

La propuesta de Rorty quiere hallar un mínimo común denominador de palabras que baste tanto para los propósitos privados como para los públicos. Son léxicos que nos sensibilicen al dolor, a la humillación.

Por otra parte, para el autor "la responsabilidad hacia el otro" se sostiene en la historia y contingencia. En este sentido la moral es una cuestión de intersubjetividades que dialogan en una comunidad, integrando un léxico común, como algo restringido y más local que un lenguaje que hace referencias a un mundo de esencias. El autor afirma que lo que efectivamente "nos une con el resto de la especie, es esa forma especial de dolor que los brutos no comparten con los humanos: humillación" ${ }^{23}$. Efectivamente, a la pregunta ¿cómo se realiza la responsabilidad hacia el otro?, Rorty, si bien formula una ética a partir de la creación e incremento de los sentimientos de solidaridad entre los hombres, ésta se sostiene en "la capacidad de ser susceptibles al dolor", a la humillación. La última grada que sostiene la solidaridad sería la sensibilidad como fuente principal de una ética efectiva en el terreno de la vida vivida, la vida social.

Para Rorty, el trasfondo de la pregunta que guía nuestra investigación tiene dos elementos que convergen en la respuesta de la tesis: la crítica a la filosofía europea por una parte, y la reformulación del pragmatismo y la narrativa por otra ${ }^{24}$. En efecto, la impostación

\footnotetext{
22 R. Rorty. Contingencia, ironía y solidaridad, 110-111.

23 R. Rorty. Contingencia, ironía y solidaridad, 110.

24 Rorty abandona la filosofía tradicional por considerarla innecesaria en su proyecto ético, pues afirmar una naturaleza humana común no garantiza el compromiso de los sujetos con los demás. Con esto se desmarca del esencialismo típico de la metafísica, que en La filosofía y el espejo de la naturaleza rastrea al explicar el esfuerzo engañoso
} 
a-temporal propia de la metafísica ha llevado en este sentido al Occidente a desvincular la ética de las cuestiones vitales de la existencia del ser-humano. Al final, en la vida vivida, lo que opera en las obligaciones morales no son más que resoluciones de "intereses" y no una afirmación de teorías metafísicas de la persona humana como fuente de la misma obligación. Entonces estando así las cosas, ¿qué hacer si esta correspondencia abstracta no sirve en las relaciones intersubjetivas? Pues el nudo de la solidaridad, entendido desde la metafísica, se ha tornado poco efectivo entre los seres humanos. Por ende ¿cómo desatarlo? Rorty propone crear una ética basada en la solidaridad, sustentada en léxicos cercanos y contingentes, al interior de una comunidad que él denomina, siguiendo a Sellars ${ }^{25}$, "nosotros". Por tanto, para comprender cómo el autor llega a formular una solidaridad basada en la susceptibilidad o sensibilidad por el dolor, debemos recorrer en forma breve dos momentos necesarios en su planteamiento. Justamente, el autor, al avalar la sensibilidad en tanto fuente de la ética, implica:

1. La comunidad lingüística, pues la sensibilidad requiere de un lenguaje común.

2. La comunidad etnocéntrica en tanto práctica social producto y productora de lo lingüístico.

de eternizar el discurso con fundamentos filosóficos, cuando en la realidad lo que existe es la contingencia, el mundo de las diferencias, el pluralismo. El discurso tradicional opera con la idea de la "representación" de la naturaleza, fundando así el conocimiento con la metáfora del espejo que captura las representaciones o esencias de la realidad (ver pág. 20). Rorty opera un deconstructivismo que busca una salida a la ética del siglo XX: la afirmación de la diferencia y subjetividad que permitirá valorar al extranjero, al marginal, al "ellos" (J. L. Rodríguez, Crítica de la razón postmoderna, 194-198). Por lo tanto, la tarea es evitar la tentación de dominar, "privilegiar a uno de los muchos lenguajes en los que habitualmente describimos el mundo o nos describimos a nosotros mismos" (R. Rorty. Contingencia, ironía y solidaridad, 27). Se trata de un lenguaje como juego, el que es contingente y siempre propenso a la redescripción, es decir, susceptible a ser cambiado por aquel que sea más cercano. ¿Cómo? Comparando los léxicos entre sí y no como algo fuera de ellos, asumiendo el que sea más interpelante.

25 Ver nota 28. 
3. La "sensibilidad" con el supuesto de un hábitat lingüístico y social se instituye en tanto fuente de la ética: producto de la contingencia de los léxicos y prácticas sociales.

\subsection{La sensibilidad y la comunidad etnocéntrica como hábitat del "nosotros"}

En la actualidad la "solidaridad humana se ha tornado imposible" debido a la forma tradicional de explicarla recurriendo a "nuestra humanidad esencial, que resuena ante la presencia de eso mismo en otros seres humanos ${ }^{\prime 26}$. Al final esta teoría se desploma. Rorty, su teoría ética basada en la solidaridad la identifica "como una cosa creada... obligación con validez intersubjetiva... [que] puede remitir a todos los miembros" 27 de esa comunidad. El autor, siguiendo a Wilfrid Sellars, considera la obligación moral en términos de "intenciones-nosotros", o sea se trata de que la responsabilidad ética siempre es hacia "uno-de-nosotros" 28.

Desde este enfoque, la solidaridad es vista como una cuestión común entre los miembros de la comunidad. No hay fundamentos sino más bien creencias, deseos y "sensibilidades" que nos identifican con el resto del grupo para los fines de la liberación política y moral. El autor afirma que es mucho más persuasivo describirnos por ejemplo como compatriotas -en el caso de la nacionalidad- que como humanidad o raza humana, pues nuestro sentimiento de solidaridad se fortalece más en un sentido restringido y más local, debido a que se trata de "uno-de-nosotros". En cambio la otra explicación abstracta como el caso de "humanidad" es poco convincente y débil29.

Rorty apuesta por la fuerza del "nosotros" en un sentido etnocentrista. La forma correcta de leer el "nosotros" es en "un sentido

26 Cf. Contingencia, ironía y solidaridad, 207.

27 R. Rorty. Contingencia, ironía y solidaridad, 213: lo que está entre paréntesis es de propiedad mía para comprender mejor la redacción de la idea.

28 Véase W. Sellars. Science and Metaphysics, 222: citado por R. Rorty. Contingencia, ironía y solidaridad, 208. Véase también pág. 78.

29 Cf. R. Rorty. Contingencia, ironía y solidaridad, 209. 
tan concreto e históricamente tan específico como sea posible: significará cosas tales como nosotros, los liberales del siglo $\mathrm{XX}^{\prime \prime 30}$. Se trata de un "nosotros" entregado a la tarea de ensancharse, de crear un ethos aún más amplio, compartiendo la misma sensibilidad hacia la humillación, y "tal condición depende de un léxico último históricamente contingente" ${ }^{\prime \prime 1}$.

Ahora bien, Rorty mientras habla de un "nosotros", lo contrapone a un "ellos" para referirse a aquellos seres humanos que no tienen el estatuto de pertenencia denominado "uno-de-nosotros". Son ciertamente seres humanos, pero "la especie errónea de seres humanos"32 en el sentido de que no se identifican con alguna "descripción" de la comunidad. Justamente el autor pone como ejemplo la suerte que corrieron los judíos de ser ayudados o escondidos del nazismo en Dinamarca o en Italia, la que era mayor que aquellos que vivían en Bélgica (fueron entregados al exterminio), pues “ ¿decían, a propósito de sus vecinos judíos, que merecían que se los salvase porque eran también seres humanos?". De seguro no. Más bien, lo que ocurrió fue que la "descripción" bajo la cual se los identificó correspondía al resto de los daneses o italianos, y por tanto ello implicó un mayor compañerismo hacia ellos ${ }^{33}$.

\subsection{La sensibilidad como fuente de la responsabilidad}

A continuación trataremos de elucidar la relación que establece el autor entre la "sensibilidad" y la "responsabilidad" (solidaridad) hacia los demás. Se trata finalmente de analizar cada pieza que compone la tesis de nuestra investigación en Rorty, a saber, que "la sensibilidad actúa como fuente de realización de la responsabilidad ética hacia el (los) otro(s)". Por tanto, siguiendo al autor estructuraremos el presente punto en cuatro tópicos que se suceden y reclaman mutuamente. Pues

\footnotetext{
30 R. Rorty. Contingencia, ironía y solidaridad, 214-215.

R. Rorty. Contingencia, ironía y solidaridad, 210.

2 R. Rorty. Contingencia, ironía y solidaridad, 208-209.

33 R. Rorty. Contingencia, ironía y solidaridad, 209.
} 
Rorty, si bien recurre a la sensibilidad en tanto fuente de la solidaridad, esta disposición afectiva arranca de la contingencia del ser humano, y por eso mismo recurre a otro elemento que permita mantener $y$ ampliar estos sentimientos morales contingentes. Por eso el orden de los tópicos sigue así:

a) Rorty entiende la sensibilidad en tanto compasión hacia el sufrimiento. No se trata de un recurso a normas abstractas fundamentadas en la objetividad, sino en la compasión hacia la humillación de los otros-sufrientes.

b) El recurso a la compasión se debe en cierto sentido a la contingencia del hombre.

c) Los sentimientos de compasión requieren una educación, una "cultura poetizada" ${ }^{34}$ que amplíe los sentimientos de solidaridad.

d) Finalmente, la relación sensibilidad y responsabilidad en tanto solidaridad.

\section{a) Rorty entiende la sensibilidad en tanto compasión hacia el sufrimiento}

Rorty, en su teoría ética de la solidaridad, de entrada afirma que no hay más verdad en el hombre que el que "nosotros podemos sentir los unos por los otros"35, especialmente por aquellos que sufren. Ahora bien, si se trata de una responsabilidad (solidaridad), ésta es de frente al "otro". Lo que ocupa a Rorty conjuntamente con avalar la susceptibilidad por el dolor, es precisamente la susceptibilidad hacia el dolor del otro: la humillación de los miserables. ¿Acaso no está también admitiendo en su propuesta ética basada en la susceptibilidad que a pesar de la diferencia de etnia, de nación, de grupos, en el dolor somos todos iguales? Efectivamente lo que compartimos con el resto de los seres humanos es la capacidad de ser sensibles al

34 R. Rorty. Contingencia, ironía y solidaridad, 85.

35 R. Rorty. "Derechos humanos, racionalidad y sentimentalidad", 128. 
dolor; en esto somos iguales, afirmación que le permitirá dirigir una ética que incorpore el valor de la "diferencia" en ámbitos tales como la etnia, nacionalidad, partido político, etc.

A Rorty le preocupa que en el ámbito de los sentimientos como capacidad común a todos nosotros, los seres humanos, sea posible reubicar la solidaridad. Pues lo decisivo en la obligación moral serán los sentimientos de solidaridad, antes que una idea abstracta y universal de humanidad con sus derechos y deberes, que al final no se traduce adecuadamente en el plano intersubjetivo de la justicia.

Si para Rorty la solidaridad en tanto capacidad de responder por alguien encuentra su fuente de realización en el nivel de la sensibilidad o disposición afectiva por el que sufre, ¿qué relación tiene este nivel sensitivo con la ética solidaria? ¿Por qué Rorty afirma que es necesario un incremento de los sentimientos de solidaridad hacia los demás? ${ }^{36}$ Desde nuestro autor, que utiliza un concepto de la ética anclada en la contingencia del ser humano, podemos distinguir dos elementos que nos permitirán elucidar más detenidamente la relación común que tenemos todos nosotros: la sensibilidad por la humillación:

i. En el dolor somos todos iguales.

ii. En el dolor me identifico con el otro sufriente.

\section{i. En el dolor somos todos iguales}

Rorty, como ya se viene enunciando, en su concepción contingente de la solidaridad entrevera en el sujeto humano una cierta capacidad,

\footnotetext{
36 En efecto, Rorty afronta la cuestión del progreso moral en tanto "un incremento de la sensibilidad, un aumento de la capacidad para responder a las necesidades de una variedad más y más extensa de personas y cosas. Los pragmatistas no consideran el progreso científico como la atenuación gradual del velo de la apariencia que oculta la naturaleza intrínseca de la realidad, sino como la aptitud creciente de responder a las inquietudes de grupos cada vez más extensos de personas, especialmente de personas que generan las observaciones más agudas y ejecutan los experimentos más refinados. Del mismo modo, consideran el progreso moral como un estar en condiciones de responder a las necesidades de grupos de personas más y más abarcativos" (Rorty, R. ¿Esperanza o conocimiento? Una introducción al pragmatismo, 91).
} 
común a todos a pesar de los contextos y léxicos diferentes que puedan existir: la disposición sensible de padecer dolor o humillación por los demás sufrientes. La experiencia básica, que me permitirá responder ante la humillación de alguien, se resuelve en esa disposición. El vínculo es complemente afectivo, pues en la humillación del otro me veo reflejado. Se trata de una condición común a todo ser humano con independencia del tiempo y lugar. Ahora bien, si la crueldad para un hombre no es la crueldad para otro hombre, se debe a que no hay una objetividad entre los hombres a la hora de rechazar la tortura, el sufrimiento o la humillación. Rorty en este sentido afirma que "en algunos casos deploramos la crueldad y en otros casos hallamos placer en ella" ${ }^{37}$, como ocurre en el caso de un "magistrado justo y moderado y, a la vez, un padre indiferente y despectivo" ${ }^{38}$. El pulcro final de la tesis se dilucida en tejer una ética a la medida de nuestro caso individual. En efecto, Rorty pone cuidado en el tratamiento de la sensibilidad-sufriente, pues si bien es común a todos los seres humanos, no es universal en el sentido de que sintamos compasión por todos los seres humanos. Es una disposición restringida al núcleo local de la comunidad que utiliza un mismo léxico y código cultural. Por lo tanto, esta disposición sensible siempre es hacia aquellos con los cuales me identifico, porque hablan el mismo lenguaje que yo. Pertenecen a mi tribu.

Rorty, a pesar de la contingencia del Yo y de los contextos culturales, mantiene la idea de que "todos tenemos la insoslayable obligación de hacer que los seres humanos sean iguales en cuanto a su susceptibilidad al sufrimiento" ${ }^{39}$. Aunque exista una diversidad de situaciones, las posibilidades de ser benévolos se sostienen en un vínculo ético que arranca a partir del "reconocimiento de la condición común de ser susceptibles a la humillación" ${ }^{40}$. En esto somos iguales, afirma Rorty, es decir, la experiencia de fragilidad se desprende de su visión ironista

37 R. Rorty. Contingencia, ironía y solidaridad, 52.

38 R. Rorty. Contingencia, ironía y solidaridad, 51.

39 R. Rorty. Contingencia, ironía y solidaridad, 106.

40 R. Rorty. Contingencia, ironía y solidaridad, 109. 
de un Yo "tejido de contingencias" ${ }^{41}$, un yo no asegurado sino por asegurar continuamente. Pero ¿basta esta experiencia común como para solidarizar con los demás? El autor, al afirmar esta disposición común en los seres humanos, agrega otro elemento que le permitirá conectar humillación y responsabilidad, idea que desarrollaremos más detenidamente en el siguiente punto (2).

\section{ii. En el dolor me identifico con el otro sufriente}

Para nuestro autor no existen sentimientos objetivos o deberes morales categóricos que nos muevan hacia ciertos bienes morales. Se trata de sustituir la idea kantiana de una "Voluntad Buena por la idea de un ser humano cálido, sensible y compasivo" ${ }^{42}$.

No solo basta esta capacidad de sentir conmiseración hacia los demás ${ }^{43}$, sino que es necesaria la presencia de otro elemento que Rorty declara. Se trata de que en el sufrimiento de los demás me vea reflejado como compañero de camino en el dolor, es decir, para el autor "sentir" en este sentido sería la capacidad de conmiseración propia en el dolor ajeno. En el dolor ajeno me siento interpelado, conmovido por esa humillación que también puede ser la mía propia ${ }^{44}$. Por tanto,

41 R. Rorty. Contingencia, ironía y solidaridad, 52.

42 R. Rorty. ¿Esperanza o conocimiento? Una introducción al pragmatismo, 94.

43 Rorty a propósito de los Derechos Humanos alude al tema de la maleabilidad de los sentimientos: "Quienes desean proporcionar fundamentos racionales, filosóficos a una cultura de derechos humanos dicen que lo que los seres humanos tienen en común sobrepasa los factores adventicios como la raza o la religión. Pero tienen problemas a la hora de decirnos en qué consiste esta comunalidad. No basta con decir que todos comparten una susceptibilidad común al dolor. Si lo que importara fuera el dolor. sería tan importante proteger a los conejos de los lobos como proteger a los judíos de los nazis. Si aceptamos el enfoque naturalista, darwiniano, de los orígenes humanos, no sirve decir que tenemos en común la razón, porque, en ese enfoque, ser racional es, sencillamente, ser capaz de usar lenguaje. Pero hay muchos lenguajes y la mayoría de ellos es excluyente. El lenguaje de los derechos humanos es una característica de nuestra especie, ni más ni menos que los lenguajes que insisten en la pureza racial o religiosa" (R. Rorty. ¿Esperanza o conocimiento? Una introducción al pragmatismo, 99). 44 En efecto, Rorty afirma que la utopía que él persigue no aparecerá mediante un hecho a reconocer o "yéndose a esconder a profundidades antes ocultas, sino, más bien, como una meta por alcanzar. No se ha de alcanzar por medio de la investigación, 
"el ser susceptibles de padecer dolor" ${ }^{45}$ explica tanto al sufriente como al sentiente, puesto que este es el lazo que los une. El filósofo agrega que se trata de "una esperanza egoísta común" 46 , y como a todos nos afecta, la idea es tomar parte en la construcción de una sociedad más solidaria eliminando la crueldad. Se refiere a "una esperanza egoísta común" en el marco de su proyecto de una utopía liberal cuyos miembros a partir de la metáfora puedan "crearse a sí mismos" 47 sin la referencia a un léxico "fuera de la comunidad". Nuestro autor, al despojar al hombre de toda referencia y vínculo meta-histórico, apuesta por una sociedad liberal compuesta por individuos que puedan "hallar sus propias metáforas para sus propias fantasías privadas" aunque éstas sean "vagamente sentidas por el resto de la sociedad", ya que se trata de una sociedad sin un léxico absoluto que uniforme las individualidades de los sujetos. Entonces ¿qué queda como individuos que vivimos en sociedad? Rorty a partir de aquí afirma su tesis: el vínculo social que nos une con el resto de los seres humanos es la disposición sensible de padecer humillación. Sobre esa base levanta el edificio de la solidaridad en las sociedades liberales.

A partir de este sentido de sociedad liberal podemos decir con Rorty que lo que le afecta a "uno-de-nosotros" ${ }^{48}$ afecta la utopía de una

sino por medio de la imaginación, por medio de la capacidad imaginativa de ver a los extraños como compañeros en el sufrimiento. La solidaridad no se descubre, sino se crea, por medio de la reflexión. Se crea incrementando nuestra sensibilidad a los detalles particulares del dolor y de la humillación de seres humanos distintos, desconocidos para nosotros. Una sensibilidad incrementada hace más difícil marginar a personas distintas a nosotros, pensando: 'No lo sienten como lo sentiríamos nosotros', o 'Siempre tendrá que haber sufrimiento, de modo que ¿por qué no dejar que ellos sufran?'" (R. Rorty. Contingencia, ironía y solidaridad, 18).

45 R. Rorty. Contingencia, ironía y solidaridad, 110.

46 R. Rorty. Contingencia, ironía y solidaridad, 110.

47 Rorty desarrolla estas ideas en los capítulos I y II de Contingencia, ironía y solidaridad, donde da cuenta de la necesidad de curarse de la metafísica y quedarse en la contingencia de nuestro "yo" y la capacidad de una "creación de sí mismo" a partir de aquellos léxicos más idóneos a nuestras aspiraciones. Se trata de dejar de lado aquellas "viejas palabras", pues "tanto para la comunidad como para el individuo, el progreso es cuestión del uso de nuevas palabras", R. Rorty. Contingencia, ironía y solidaridad, 68. 48 Cf. R. Rorty. Contingencia, ironía y solidaridad, 210. 
sociedad más justa, solidaria y menos cruel ${ }^{49}$. La moral es una cuestión de prácticas sociales que nosotros hacemos con "propósitos de protección mutua" ${ }^{50}$. Por ende cuando Rorty insiste en que la sensibilidad ante el dolor humillante pasa por la capacidad de advertir el dolor e identificarse con ellos-sufrientes, afirma que la ligazón que nos une con los demás a nivel ético se resuelve en esta capacidad sensitiva hacia el dolor sufriente. Porque el "sentido de la solidaridad humana se basa en el sentimiento de un peligro común" ${ }^{51}$, pues en la humillación del otro me veo reflejado igualmente.

El autor, desde su postura ironista ${ }^{52}$, desarraiga al sujeto humano de una vinculación social que se sostenga en alguna teoría esencialista. No existiría un yo universal al cual el sujeto deba conformarse, o un deseo innato de alteridad basado en la bondad del ser. Los que existen son individuos que buscan su "mejor yo" y que en tanto viven en sociedad deben procurar cultivar sus sentimientos de solidaridad. La preocupación o solidaridad hacia "uno-de-nosotros" surge en tanto me siento interpelado en el dolor, me toca afectivamente porque en ese otro-sufriente me identifico.

\section{b) El recurso a la compasión se debe principalmente a la contingencia del sujeto humano}

Pero bien, si Rorty reubica la solidaridad al interior de una comunidad lingüística y etnocéntrica, lo hace en el sentido que tiene más eficacia ya que todos los miembros de esa comunidad la entienden en un mismo sentido. ¿Por qué Rorty, aun en este contextualismo, recurre a la sensibilidad? ¿Acaso no se entiende que al interior de una comunidad cuyos miembros comparten las mismas creencias la solidaridad de por

\footnotetext{
49 Rorty pone la realización de un proyecto de sociedad menos cruel y más solidaria en las esperanzas de una sociedad liberal. Se trata de re-describir una sociedad que sea capaz de responder mejor a las necesidades de los seres humanos, por ello es necesario iniciar un progreso moral con el uso de nuevas palabras: nuevas metáforas que nos ayuden a ser solidarios entre sí (Cf. R. Rorty. Contingencia, ironía y solidaridad, 63-73).

50 Cf. R. Rorty. Contingencia, ironía y solidaridad, 78.

51 R. Rorty. Contingencia, ironía y solidaridad, 109.

52 Ver nota 32.
} 
sí tendría más eficacia? O sea si se trata de abandonar los fundacionismos universales y quedarse con los con-textos, ¿éstos no bastan por sí solos como para que quienes los compartan entiendan en un mismo sentido de qué se trata la solidaridad? ¿Qué otra tesis Rorty supone al plantear la creación y ampliación de los sentimientos de solidaridad? El autor, siguiendo su línea de pensamiento antifundacionista, afirma que el fracaso de los derechos humanos radica en defender una naturaleza humana siendo que "la verdad real acerca de la naturaleza humana es que somos animales excepcionalmente desagradables y peligrosos" ${ }^{\prime \prime 5}$. Se trata de una antropología darwiniana que Rorty se toma en serio, pues el ser humano no es la especie privilegiada por Dios o la naturaleza, sino aquel que surge al asumir la contingencia de su situación como algo que se debe construir. El autor ha remarcado que el darwinismo nos conduce a relatarnos "una historia sobre los seres humanos como animales con órganos y habilidades especiales: sobre cómo ciertos rasgos de la garganta, manos y cerebro de los humanos les permitieron a éstos comenzar a desarrollar prácticas sociales cada más complejas" ${ }^{24}$.

La antropología rortyana, por así decirlo, se enraíza además de la visión darwiniana del hombre, en los aportes de Freud, el que considera como "el moralista que contribuyó a desdivinizar el hombre haciendo remontar la conciencia a sus orígenes situados en las contingencias de nuestra educación" ${ }^{\prime 25}$. Porque la voz de la conciencia es la voz interiorizada de los padres y de la sociedad. En esta visión del "yo" contingente como pro-

53 R. Rorty. "Derechos humanos, racionalidad y sentimentalidad", 120. Efectivamente, Rorty lo afirma siguiendo a Nietzsche: "la auténtica verdad sobre la naturaleza humana es que somos el más sórdido y peligroso de los animales", R. Richard, Verdad y progreso, 222.

54 R. Rorty. "Putnam and the Relativist Menace", 447-448. La traducción es mía.

55 R. Rorty. Contingencia, ironía y solidaridad, 50. Para un estudio más completo ver R. Rorty. "Freud and Moral Reflection", 1-27. Según Rorty, Freud nos ayudó a desuniversalizar el sentido moral tornándolo individual. Esto nos permite ver la conciencia moral como algo históricamente condicionado. En efecto, para Freud ciertas situaciones y personas concretas producen una culpa insoportable, y además nos proporciona un modo de concebir la compasión, no como una identificación con un Yo común a todos, sino como algo encauzado por infinitas contingencias que hacen del Yo algo que podamos respetar. El yo ha sido tejido por una serie de circunstancias y conductas pasadas que nos fueron impuestas en la infancia: los padres y la sociedad. 
ducto de la sociedad, nuestro autor lee freudianamente el "sentimiento de compasión" que nos hace por ejemplo realizar infinitos esfuerzos por ayudar a un amigo y olvidarnos enteramente del dolor de otro, al que creemos amar entrañablemente; o de por qué una persona puede ser tanto una tierna madre y una despiadada guardiana de campo de concentración. Efectivamente, el "yo" se construye en un tejido de contingencias que pasan por un léxico y hábitos sociales, y que Freud nos ilustra paradójicamente porque en algunos casos deploramos la crueldad y en otros casos hallamos placer en ella. Nos ayuda a considerar seriamente la maleabilidad del ser humano en el sentido que las personas se hacen con los materiales de que disponen, y a ninguno de ellos ve como "más verdaderamente humano"56. Se trata que intentemos reemplazar el respeto racional por los sentimientos de conmiseración. Si la "responsabilidad hacia los demás" depende necesariamente de la susceptibilidad por el dolor ajeno, esa relación ética ha de tener como condición de posibilidad una conciencia atenta a la fragilidad humana. La idea es que nos eduquemos en una sensibilidad por la humillación, pues la "responsabilidad hacia el otro-sufriente" es algo que se debe construir, antes que descubrir, "producida en el curso de la historia" 57. Y para esto, la cultura debe ser poetizada posibilitando que la creación del "yo" se realice en una narrativa sentimental.

\section{c) Los sentimientos de compasión requieren una educación: una cultura sentimental}

Rorty, en su utopía liberal de una sociedad más justa que deteste y disminuya la crueldad, aspira a "hacer que los seres humanos sean iguales en cuanto a su susceptibilidad al sufrimiento... con independencia del lenguaje que hablen" 58 , en el sentido de que la actitud de experimentar dolor pertenece a todos los seres humanos, y que la tarea que se debe emprender es una cultura basada en aquellos relatos sentimentales que nos sensibilicen hacia la humillación.

58 R. Rorty. Contingencia, ironía y solidaridad, 106. 
Ahora bien, ¿cómo se logra incrementar estos sentimientos de solidaridad hacia los demás? Rorty prefiere, en su visión contingente e histórica de la ética, plantear una educación de los sentimientos de solidaridad. Se trata de una narrativa sentimental que posibilita una viva conciencia hacia la humillación de los otros. Aquí entran aquellos autores que nos han ilustrado acerca de esas historias que nos hablan del sufrimiento o la crueldad, como por ejemplo Orwell, Nabokov ${ }^{59}$, cuyos libros nos ayudan a volvernos menos crueles en nuestras prácticas sociales. Nos proporcionan un insumo riquísimo para la creación de léxicos que posibiliten una sensibilidad ética. La literatura cumple esta función: educarnos en la sentimentalidad por los demás, que por lo demás destrona a los filósofos moralistas ${ }^{60}$. Para Rorty se trata finalmente de "una recreación de la especie humana" como "proceso de adaptación"; esto hará posible una verdadera "fraternidad humana"61.

Por lo tanto, mientras nos empeñemos más en el progreso poético, se posibilitará la creación de nuevas palabras que incidan y recreen la sensibilidad humana por la humillación de los otros. En esto, Rorty sigue a Freud, afirmando que somos usuarios relativamente ociosos del lenguaje, tenemos la facultad de crear metáforas ${ }^{62}$. La fantasía inconsciente nos muestra de qué modo es posible ver la vida de todo ser humano como un poema: tenemos un inconsciente creativo. Se trata, por tanto, de la victoria final de la poesía sobre la filosofía, única capacitada en la tarea de hacernos sensibles al dolor, a la humillación ${ }^{63}$.

59 Rorty en Contingencia, ironía y solidaridad, en los capítulos VII y VIII, presenta a estos escritores con algunas de sus obras, las que nos relatan historias de dolor y humillación con el fin de recrearnos en la sensibilidad por la solidaridad. En otra obra, el mismo Rorty pone de ejemplo su país, lo que sintieron los blancos después de leer La cabaña del tío Tom fue comenzar a dejar de considerarlos como humanos de segundo orden. R. Rorty. "Derechos Humanos, racionalidad y sentimentalidad", 131.

60 Se trata de los nuevos "informantes morales" que se ocuparán de una disciplina intelectual y hegemónica: la narrativa. Son las propiedades (ética, moral) que antes ostentaba la filosofía: R. Rorty. Contingencia, ironía y solidaridad, 99 -101.

61 R. Rorty. El pragmatismo, una versión: antiautoritarismo en epistemología y ética, 212.

62 R. Rorty. Contingencia, ironía y solidaridad, 56.

63 Rorty afirma que la mente desempeña el papel que los griegos atribuían a la razón, es decir, siguiendo a Freud concuerda en que la imaginación tiene la capacidad de crear metáforas no en tanto son recuerdos de otro mundo (Platón) sino alguna cataxia 
Este desplazamiento de la filosofía hace posible que en la poesía los individuos desplieguen sus genios creativos porque la:

"imaginación es el principal instrumento del bien... el arte es más moral que toda moralidad. Porque esta última es, o tiende a ser, una consagración del statu quo... Los profetas morales de la humanidad han sido siempre poetas, aun cuando se expresaran en versos libres o en parábolas" ${ }^{\prime 64}$.

Así será posible poetizar las vidas individuales en el horizonte de la autocreación y del incremento de la sensibilidad por los demás. En este marco, el autor afirma la necesidad de poetizar los focus imaginarius, pues la solidaridad depende de un elemento retórico y narrativo ${ }^{65}$.

\section{d) Recapitulación: la relación entre sensibilidad y responsabilidad en tanto solidaridad}

Rorty afirma que "apoyarse en las propuestas del sentimiento en lugar de los mandatos de la razón" es la mejor arma para responder a la pregunta "¿por qué debo responsabilizarme por el otro?", en vez de "¿por qué debo ser moral?"66 Entiéndase responsabilidad en tanto

particular, generadora de una obsesión, de alguna persona, palabra u objeto particulares de la etapa temprana de la vida. Se trata de ver que la metáfora, la poesía pertenecen naturalmente a la constitución misma de la mente. La mente es una facultad productora de poesía. En este sentido las personas construyen su propia identidad, al contrario que los filósofos que pretendían hacerlo desde cosas universales, comunes a todo ser humano (ciega marca: Yo). Cada individuo tiene este poder creativo que le viene de la metáfora, que Rorty llama "redescribirse" a su modo propio. Estas formas de redescribirse pueden ser privadas o de la comunidad, y son todas ellas históricamente condicionadas. En fin, la redescripción creativa se basa en esta capacidad de la mente por hacer cosas nuevas e importantes en función privada o pública. Lo importantes es que no existe una única redescripción correcta, sino más bien una que mejor se acomoda a nuestras aspiraciones. Cf. R. Rorty. Contingencia, ironía y solidaridad, 57-59.

64 J. Dewey. Art as Experience, 348: citado por R. Rorty. Contingencia, ironía y solidaridad, 87.

65 R. Rorty. Contingencia, ironía y solidaridad, 210-214. Se trata de cambiar aquellos focus imaginarius que alguna vez sirvieron como "la naturaleza humana", "la verdad absoluta", etc., por aquellos más retóricos y poéticos (narrativos) que colaboran en la sensibilización ética hacia el otro.

66 R. Rorty. "Derechos humanos, racionalidad y sentimentalidad", 117 ss. 
la capacidad en responder por alguien, y en este sentido debemos entender "solidaridad". El "otro" surge como preocupación responsable en la esfera de la sensibilidad humana, ante la conmiseración del padecimiento humano: la humillación.

Rorty considera desde un sentido compasivo de la sensibilidad la relación de responsabilidad que tenemos con los demás, si bien no la fundamenta en principios. La afirmación de que tenemos una obligación moral con los demás adquiere consistencia ética, si y sólo si, en la esfera de los sentimientos. Por lo tanto, la "solidaridad" en Rorty tiene este trasfondo como primer momento o antesala a la comunidad lingüística: "susceptibilidad al sufrimiento" ${ }^{67}$. Nos referimos a la comunidad que utiliza un léxico común, y no descontextualizado en el sentido que utiliza "palabras" de un "viejo léxico último" ${ }^{68}$ que no toman en cuenta la contingencia de los individuos y la sociedad. Además insiste que se trata de tener "una avivada conciencia de la posibilidad de sufrir", de preocuparse no de una "razón" de "por qué el sufrimiento" sino de "asegurarse de que [el ironista liberal] nota el sufrimiento cuando se produce" ${ }^{\prime \prime}$. La peculiaridad del ser humano sería su susceptibilidad de ser humillado y esto precisamente lo mueve para ser solidario, y por ende justo con los suyos. Este paso hace posible solidarizar con los demás, incorporándolos en el pedestal de la igualdad, así el "otro" transita hacia el "uno-de-nosotros". Solamente cuando se concibe al otro como un "uno-de-nosotros" se buscará el bien común, la benevolencia ${ }^{70}$. Con este planteamiento Rorty deroga en su teoría todo fundamentalismo metafísico y sitúa la "sensibilidad" del ser humano como el móvil del progreso moral.

Recapitulando, hasta aquí Rorty afirma que las obligaciones o responsabilidades éticas que tenemos con los demás, si bien dependen de un léxico común y una pertenencia a una comunidad, involucran necesariamente la capacidad de ser susceptibles al dolor. Efectiva-

\footnotetext{
67 R. Rorty. Contingencia, ironía y solidaridad, 106.

68 R. Rorty. Contingencia, ironía y solidaridad, 116.

69 R. Rorty. Contingencia, ironía y solidaridad, 111.

70 Cf. R. Rorty. Contingencia, ironía y solidaridad, 208.
} 
mente "la conmiseración ante el dolor y el remordimiento por la

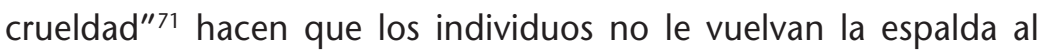
sufrimiento humano. El sentido de responsabilidad hacia los demás se realiza ${ }^{72}$ en tanto una disposición sensible hacia el dolor que me interpela compasivamente por el otro-sufriente. Me con-mueve. Pero preguntémonos ahora: ¿por qué me interpela el otro-sufriente? Rorty, al no fundamentar filosóficamente la relación ética que tenemos con los demás, sostiene que nuestra responsabilidad depende de un factor compasivo en tanto se dirija hacia el sufrimiento de uno-de-nosotros. No se trata de recurrir a una especie de primeros principios para ser solidarios, sino de tener una sensibilidad o viva conciencia compasiva. En esta esfera, Rorty vislumbra un sentido de compañerismo de camino entre los hombres que en tanto individuos buscan su identidad, con tal de no provocar más crueldad, más humillación con quienes no "hablan" como "nosotros". Como "no hay nada en lo profundo de nosotros, no hay una naturaleza humana común, no hay ninguna solidaridad humana constitutiva, que pueda usarse como punto de referencia moral". ${ }^{73}$ Rorty entrevera en la "facultad de experimentar dolor" común a todos, el fundamento, por así decir, de la ética.

Si bien, en Rorty no podemos hablar propiamente de fundamentos, no quita que en su "utopía de una sociedad liberal" que tienda a repudiar la crueldad e incrementar la solidaridad, se ocupe de una ética que hay que comenzar a crear en tanto una educación de los sentimientos. Por ende, debemos afirmar a partir de nuestra investigación, que el autor igualmente intenta localizar una fuente de la responsabilidad ética, a pesar de la contingencia del sujeto humano. Una sensibilidad, que debe ser adquirida mediante una educación sentimental basada en la literatura, la poesía, el arte. Por otra parte, el autor al igual que

\footnotetext{
71 R. Rorty. Contingencia, ironía y solidaridad, 211.

72 Aquí ocupo el verbo "realizar" en tanto sinónimo de "cumplir", efectuar", "ejecutar", "actuar". Se trata de una pregunta descriptiva antes que de fundamentos. Por eso más que fundamentar la posición rortyana (cosa que ni el mismo Rorty hace) nuestra investigación quiere mostrar cómo en él y Lévinas la responsabilidad en tanto "responsabilidad" se realiza a partir de la sensibilidad.

73 R. Rorty. Contingencia, ironía y solidaridad, 195.
} 
los postmodernos, otorga un merecido privilegio a lo poético en el sentido que como forma expresiva desplaza el saber filosófico por uno concreto e inmediato que atiende el devenir de la existencia humana. ¿Por qué la poesía? En el escenario de la postmodernidad, la poesía reaparece como antítesis del logos, y como reivindicación de la subjetividad irreductible al conocimiento. Se trata de aquella palabra poética que es capaz de presentar la ausencia de la subjetividad en el pensamiento totalizante: el sufrir. En efecto, lo "poético es la praxis insólita que deja huella de una diferencia imborrable que, en sí misma, niega la convención del pensar o certifica que el pensar debe radicarse en la expresión del sufrir"74. La poesía esclarece el dolor, pero cuando es llevado al pensar, se vuelve delito al no poder comunicar lo inconmensurable de esas vivencias que pertenecen de suyo al ser humano. En este sentido Rorty apuesta por la poesía en tanto una forma de expresión que traduce, comunica y resuena en las conciencias humanas el dolor, la humillación.

El sentido de la ética rortyana hace de la sensibilidad su fuente. Es una apuesta alternativa a la indagación filosófica. Pone al ser humano sin argumentos sólidos, sin apoyos en la naturaleza humana. El autor se niega a reconocer que la naturaleza humana sea capaz de brindar un soporte para la solidaridad. Se trata de concebir la solidaridad como un constructo histórico ${ }^{75}$ y no como el resultado de un sentimiento humano, el que puede ser tan dócil tanto al amor como al odio ${ }^{76}$. En efecto, en el marco de la contingencia el sujeto humano -desprovisto de una esencia humana y un deseo benigno hacia la "humanidad"es el resultado de las circunstancias históricas, un yo que consiste en un tejido de contingencias en virtud de aquellos léxicos que mejor se ajusten a nuestras aspiraciones. Así, desprovistos de un "yo central" nos tejemos una moral individual a nuestra medida: individual y so-

\footnotetext{
74 J.L. Rodríguez. Crítica de la razón postmoderna, 125.

75 R. Rorty. Contingencia, ironía y solidaridad, 213.

76 Rorty al concebir al yo moral sin fundamentos metafísicos sino en tanto una red de creencias, deseos y emociones (no una naturaleza fija) sino un proyecto abierto, libre e inacabado. En este sentido el autor afirma de los seres humanos que son "animales flexibles, proteicos, maleables". R. Rorty et al. Batallas éticas.
} 
cial. Rorty, siguiendo a Freud, renuncia a un concepto de ser humano universal y se queda con uno contingente, que siente compasión por quienes le interpelan por diversas razones: etnia, afectividad, léxico común, pertenencia al mismo grupo, etc. Por eso que los sentimientos de compasión se tejen con aquellos cercano, con aquellos que son como "uno-de-nosotros". Lo que finalmente propone el autor es ampliar el sentido de la solidaridad de manera que puedan muchos más entrar a formar parte de un "nosotros" solidario. Una cultura de la solidaridad necesita un vuelco a la sensibilidad a través de la educación, que nos domestique hacia el repudio de la crueldad e incremente nuestros sentimientos de la solidaridad. Rorty afirma al respecto:

"deseo reemplazar esa historia por una historia de la creciente disposición a vivir con la pluralidad y a dejar de preguntarse por la validez universal. Deseo ver que se llega libremente al acuerdo como acuerdo acerca del modo de cumplir propósitos comunes (por ejemplo... el control... de las personas, la igualación de posibilidades de vida, la disminución de la crueldad)"

\section{Bibliografía}

BAUMAN, Z. La posmodernidad y sus descontentos, Madrid, Akal, 2001.

BERNSTEIN, R. "Serious Play: The ethical-political horizon of Jacques Derrida", 1987. En: W. Torrey Harris (ed.) The Journal of speculative philosophy, Vol. I, n. 2, pp. 93-115.

CABANCHIK S. et al. El giro pragmático en la filosofía, Barcelona, Gedisa S.A. 2003.

COHEN, H. Religión de la razón desde las fuentes del judaísmo, Barcelona, Anthropos, 2004.

77 R. Rorty. Contingencia, ironía y solidaridad, 86. Rorty se empeña por "producir generaciones de estudiantes amables, tolerantes, prósperos, seguros y respetuosos con los demás en todas partes del mundo". Mientras podamos criar así nuestros jóvenes, más fuerte será el sentido de solidaridad efectiva hacia los que sufren humillaciones. Se trata de repudiar el dolor sensibilizándonos en el dolor. R. Rorty. "Derechos humanos, racionalidad y sentimentalidad", 130. 
CRITCHLEY, S. "Desconstrucción y pragmatismo: ¿es Derrida un ironista privado o un liberal público?" En: Ch. Mouffe (comp.). Desconstrucción y pragmatismo, Buenos Aires, Paidós, SAICF, 1998.

FIGUEROA, M. - Dorando, M. Filosofía de la Solidaridad: estudios sobre Apel, Rawls, Ricoeur, Lévinas; Dussel, Derrida, Rorty y Van Paijs, Santiago, Universidad Alberto Hurtado, 2007.

HALLWARD, P.; Badiou: a subjetct to truth, Minneapolis, University of Minnesota Press, 2003.

RODRÍGUEZ, J. L. Crítica de la razón postmoderna, Zaragoza, Biblioteca Nueva. Prensas Universitarias de Zaragoza, 2006.

RORTY, R. "Putnam and the relativist menace" En: The Journal of Philosophy, vol. XC, no. 9, pp. 443-461, 1993.

Contingencia, ironía y solidaridad, Barcelona, Paidós, 1996.

Derechos humanos, racionalidad y sentimentalidad", 1998.

En: Shute, S. et al. Derechos humanos. Las conferencias Oxford Amnesty de 1993, Madrid, Trotta.

. El pragmatismo, una versión: antiautoritarismo en epistemología y ética, Barcelona, Ariel, 2000.

Esperanza o conocimiento?: una introducción al pragmatismo, Buenos Aires, FCE, 2001.

SALVAT, P. El porvenir de la equidad. Aportaciones para un giro ético en la filosofía política contemporánea, Santiago, LOM-Universidad Alberto Hurtado, 2002.

SELLARS, W. Science and Metaphycis, Atascadero CA., Ridgeview Publishing Company, 1967.

TOWARNICKI, F. DE - PALNIER, J. M. Conversación con Heidegger, En: L`Express, no. 954, 1969. 